\title{
Who Gives a Hoot?: Intercept Surveys of Litterers and Disposers
}

\author{
Renée J. Bator, ${ }^{1}$ Angela D.Bryan, ${ }^{2}$ and P.Wesley Schultz ${ }^{3}$
}

\section{Abstract}

Across 14 different outdoor settings in 8 states, the authors interviewed 102 disposers to examine how littering behavior is affected by environ- mental factors, social norms, demographic characteristics, and self-reported motivations. Observations revealed that 25\% of all disposals were littered, and the most commonly littered item was cigarette butts. Participants were less likely to litter in locations with more receptacles available and with receptacles positioned so they could be easily reached. Younger participants, who reported weaker personal norms against littering, were more likely to litter. Implications of this work suggested the necessity of adequate receptacle availability and accessibility, especially cigarette-butt receptacles. In addition, antilittering campaigns were advised to direct their appeals to those most at risk for littering - targets under the age of 30.

\section{Keywords}

environment, pollution, recreation, social norms

${ }^{1}$ State University of New York, Plattsburgh ${ }^{2}$ University of New Mexico,Albuquerque ${ }^{3}$ California State University, San Marcos

\section{Corresponding Author:}

Renée J. Bator, Department of Psychology, State University of New York, SUNY Plattsburgh, Plattsburgh, NY 12901

Email: renee.bator@plattsburgh.edu 


\section{Intercept Surveys of Litterers and Disposers}

Litter negatively impacts our communities in terms of aesthetic, environmental, and financial costs. Beginning in the 1960s, Keep America Beautiful began investigations of littering behavior that led to widespread media campaigns and a growing awareness of litter. Since then applied research investigations have been conducted to examine the predictors of proenvironmental behavior, like littering, and these studies generally focus on one of four domains: facilitators in the built environment, explicit proenvironmental messages, social normative information, and individual difference factors.

\section{Environmental Facilitators}

Across the many existing studies of littering, structural elements of the built environment have consistently emerged as important determinants of littering. Clearly, a major facilitator of antilittering behavior is the availability of trash receptacles. People are simply less likely to litter if there are trash receptacles, particularly if the receptacles are appropriate and easily accessible. Finnie (1973) positioned trash receptacles in key locations on roadways and city sidewalks and measured littering rates at those sites. Comparisons were made between times when the receptacles were available versus removed. As expected, the observations revealed substantial reductions in litter when receptacles were made available. Finnie found that the presence of receptacles decreased litter by $28.6 \%$ in highway locations and by $16.7 \%$ in city sidewalk locations. These findings emphasize the importance of receptacle availability in terms of curtailing litter among both drivers and pedestrians.

Similar results were reported by Geller, Brasted, and Mann (1980), who showed that the appropriateness of the trash receptacle influenced littering behavior in an indoor mall setting. They coded items in ashtrays as appropriate (e.g., cigarette butts and matches) or inappropriate (e.g., candy, 
paper, gum, etc.) and found that ashtrays with attached trash receptacles (e.g., an appropriate receptacle for each kind of litter) had the lowest rate of inappropriate litter. Those ashtrays without an attached trash receptacle or ashtrays with no trash receptacle nearby had the highest rate of inappropriate litter.

In addition to the presence and appropriateness of trash receptacles, the distance one has to travel also predicts littering. In an observational analysis of actual littering behavior, Meeker (1997) examined table littering in two different indoor settings: in the dining room of a fast-food restaurant and in the lounge of a university library. Although there were few differences between littering behaviors in the two settings, Meeker found a positive correlation between littering rates and patrons' distance to receptacles.

In sum, the characteristics of the built environment that facilitate proenvironmental behavior are, unsurprisingly, the availability, appropriateness, and proximity of trash receptacles. But even when appropriate and nearby receptacles for litter disposal are made available, littering behavior persists, which suggests that there are other important determinants of littering behavior.

\section{Social Normative Information}

A well-documented finding among researchers who study littering behavior is the increased likelihood of littering in a littered setting compared to a clean setting (e.g., Finnie, 1973; Geller, Witmer, \& Tuso, 1977; Heberlein, 1971; Krauss, Freedman, \& Whitcup, 1978). Researchers who study social norms explain that the inclination to refrain from littering in clean settings is a result of the power of descriptive norms, which are the norms regarding the prevalence of a given behavior. A clean setting sends a message that the universal behavior in that location is to refrain from littering. Cialdini, Reno, and Kallgren (1990) conducted a series of studies to examine the impact of norms on littering behavior. In their first three studies, the researchers repeatedly found that littering occurred at higher rates in the settings that they manipulated to be 
heavily littered - in this case a prolittering descriptive norm was activated. The researchers concluded that norms can powerfully motivate human action. In terms of littering behavior, individuals are much more likely to litter in set- tings where the presence of litter demonstrates a prolittering descriptive norm. Another factor related to social normative information is the number of other people present in the setting. Durdan, Reeder, and Hecht (1985) considered that prosocial behavior tends to decrease when there are more people present, based on diffusion of responsibility (Latané \& Darley, 1969). How- ever, it is important to distinguish between group size (which is the size of one's immediate social circle) and crowding (which is based on density of the total number of people at a given site). Latané and Darley found that people were least likely to intervene in emergency situations when the group was larger. Likewise, Durdan et al. found that college students were least likely to bus their cafeteria trays when they were seated in larger groups. A similar study of table littering revealed that littering increased with the number of persons at a table (Meeker, 1997). However, these studies all focus on group size, meaning the number of people who are together with the target individual. We are unaware of research that has examined how the overall crowding or density of bystanders in the setting impacts littering. 


\section{Explicit Proenvironmental Messages}

Social norms could be considered an implicit message about acceptable littering behavior. In an effort to motivate reduced littering behavior, litter-control researchers have also tested the effectiveness of explicit proenvironmental messages. Reich and Robertson (1979) examined littering behavior at an out- door public swimming pool. Patrons at the pool concession stand received a flyer that was either designed to encourage support of social standards (i.e., "Help keep your pool clean") or one with a more threatening message (i.e., "Don't litter"). The authors expected that the latter message would be ineffective because it could lead to reactance. Trash receptacles were readily available at all times, and no effort was made to modify the cleanliness of the setting. As expected, there were significantly more threatening message flyers littered than those with the social standards message. The authors explained that messages that are perceived to demand specific behaviors may backfire as a result of reactance. Instead, those messages with a social norm manipulation were much more likely to promote the desired behavior. It is not clear whether the proenvironmental, social norm-supporting messages work even in a heavily littered environment.

Further research on the impact of messages on littering behavior was con- ducted in a university cafeteria (Durdan et al., 1985). Messages were posted on patrons' tables that were either positively worded or negatively worded and general or specific in terms of discouraging litter. The researchers found a main effect for the direction of the message, with significantly less litter occurring among patrons seated at tables with positively framed messages; however, there was no effect for the specificity prompt and no interaction. Durdan et al. were somewhat surprised that their mildly negative messages (i.e., "Please don't litter") resulted in a significant increase in litter, yet they consider reactance to be the motivating factor behind this behavior change. Reiter and 
Samuel (1980) examined how littering rates in a parking garage are affected by the use of signs as well as manipulations of differential amounts of litter in the setting. They compared a threatening sign (i.e., "Littering is Unlawful and Subject to a US\$10 Fine") to one that emphasized cooperation (i.e., "Pitch In") as well as a control condition with no sign present. The authors were surprised to find no difference in the littering rates between the two types of signs, although they did find that littering was lower with either sign compared to no sign. Their key finding was a main effect for the state of the environment. The participants in the parking garage were much more likely to litter in the littered setting than the clean one. This is consistent with Cialdini et al.'s (1990) study of descriptive norms and provides further evidence that litter begets litter. Yet the lack of an effect for the different messages suggests that further research is needed into wording that will encourage people to refrain from littering. The evidence that does exist suggests that some message communicating a proenvironmental social norm is more effective than no message at all.

Overall, messages directing antilittering are most likely to be successful if they avoid creating a feeling of reactance. Although findings are mixed in terms of the most effective wording for messages, there is a trend for positively framed messages to be more successful, and any message discouraging litter seems to work better than no message. But it is also important to con- sider how individual differences affect littering behaviors.

\section{Individual Differences}

In an effort to understand whether there are particular groups of people who litter more and thus might be targeted with specific littering prevention efforts, investigators have examined both demographic and personality factors. Research in other areas related to prosocial behavior suggests that gender might play a strong role in littering behavior. Generally speaking, in our culture, women tend to focus more on being 
neat and clean (Durdan et al., 1985) and to have reported a greater overall concern about the environment (Zelezny, Chua, \& Aldrich, 2000). The role of gender in the specific domain of littering, however, seems to be equivocal, with some researchers finding that women are less likely to litter (e.g., Meeker, 1997) and others finding no gender difference (Finnie, 1973). A second individual difference factor that has been examined is age. A number of studies have found a trend for younger people to litter more often than those who are older (e.g., Durdan et al., 1985; Finnie, 1973; Heberlein, 1971; Keep America Beautiful, 1968; Krauss et al., 1978). Krauss et al. explained that as people mature the socialization process promotes normative control. Similarly, Casey and Scott (2006) found that older individuals reported more environmental concern than younger individuals.

Cialdini, Kallgren, and Reno (1991) were interested in whether there are personality differences in the extent to which being someone who does not litter is incorporated into an individual's self-concept. Cialdini et al. (1991) developed the Personal Norm Against Littering (PNAL) Scale to measure this trait. The scale is comprised of 10 items asking about the extent to which respondents feel a personal obligation not to litter in a variety of situations (e.g., when you are holding a gum wrapper and there are no trash cans avail- able). Response options on the scale ranged from 1 (no personal obligation for me) to 9 (very strong personal obligation for me).

In a study of antilittering Public Service Announcements (PSAs), Bator's (1997) participants completed the PNAL Scale during an initial omnibus testing session and were later recruited to participate in a seemingly unrelated study. Participants watched PSAs imbedded within television programming. After a delay all participants were given an opportunity to litter. The data indicated that the PNAL Scale was a significant predictor of actual littering behavior. More recently, Kallgren, Reno, and Cialdini (2000) administered the scale to participants before they began an ostensibly irrelevant laboratory experiment. Like Bator, the main measure in this study was an unobtrusive observation of participants' littering. 
Kallgren et al. also found less littering among participants with a stronger personal norm against littering. This provides good evidence that the scale has been found to predict behavior, regardless of whether there is a delay between administration of the scale and observation of behavior. In sum, evidence suggests that the PNAL Scale could be a useful tool to identify potential litterers and thus more effectively design antilittering appeals.

\section{Study Overview}

The current study was an exploratory investigation of unobtrusively observed littering behavior of pedestrians in outdoor settings in which important built environment factors (i.e., presence, characteristics, and location of receptacles), explicit and implicit social norms for littering, demographic characteristics of the participants, and their self-reported motivation to not litter were simultaneously examined in naturalistic settings. From April to July 2008, researchers were trained to conduct observations and survey intercepts of pedestrians in a total of 14 different outdoor sites (10 different city-center sites, one recreation site, and three fast-food sites) in suburban and urban cities in Arkansas, California, Georgia, Kentucky, New Mexico, Nevada, New York, and Vermont (see Table 1). The goal of the project was to examine important determinants of littering behavior across a range of geographical locations and settings, to explore the generalizability of previous findings, and potentially bring coherence to discrepancies in the literature.

In a separate manuscript, we report the aggregated macrolevel findings for observed littering behavior in 130 outdoor locations (Schultz, Bator, Large, Bruni, \& Tabanico, 2009). In the current article, we report the micro- level findings from a separate series of individual intercept interviews. These interviews were conducted after researchers observed an individual dispose of an item, then intercepted the person and conducted a short interview. 
Table 1. Intercept Locations

\begin{tabular}{|l|l|l|l|l|}
\hline State & City & Category & $\begin{array}{l}\text { Location } \\
\text { Type }\end{array}$ & $\begin{array}{l}\text { Number of } \\
\text { Intercepts } \\
\text { Completed }\end{array}$ \\
\hline AR & Little Rock & Urban & City center & 2 \\
\hline AR & $\begin{array}{l}\text { North Little } \\
\text { Rock }\end{array}$ & Suburban & City center & 8 \\
\hline CA & Carlsbad & Suburban & Fast food & 3 \\
\hline CA & San Diego & Urban & City center & 3 \\
\hline CA & San Diego & Urban & Recreation & 4 \\
\hline GA & Marietta & Suburban & City center 1 & 5 \\
\hline GA & Marietta & Suburban & City center 2 & 7 \\
\hline KY & Jeffersontown & Suburban & Fast food & 2 \\
\hline KY & Louisville & Urban & City center & 4 \\
\hline NM & Albuquerque & Urban & City center & 14 \\
\hline NV & Henderson & Suburban & City center & 9 \\
\hline NY & Plattsburgh & Suburban & Fast food & 15 \\
\hline VT & Burlington & Urban & City center 1 & 1 \\
\hline VT & Burlington & Urban & City center 2 2 & 25 \\
\hline Total Number of Intercepts Completed & 102 \\
\hline
\end{tabular}

Our main hypotheses drawn primarily from the literature were that participants would be least likely to litter in settings with receptacles present and nearby. We also expected that less littering would occur in settings that had less litter present. We predicted that people would litter less when they were alone rather than when they were in a group. In addition, we wanted to explore how the overall crowding of the site affects littering. We also expected that older people would litter less than younger people. Finally, we predicted that those who did not litter would have stronger antilittering personal norms, as assessed with the PNAL Scale.

\section{Method}

Respondents

The respondents were 102 pedestrians in outdoor settings (men $=59$, and women $=43$ ). Their ages ranged from 18 to 83 years $(M=37)$. 


\section{Procedures}

The specified sites selected for the intercept surveys were the result of a stratified sampling procedure. Initially, we sampled regions of the country, states, cities, types of sites, and finally specific locations.

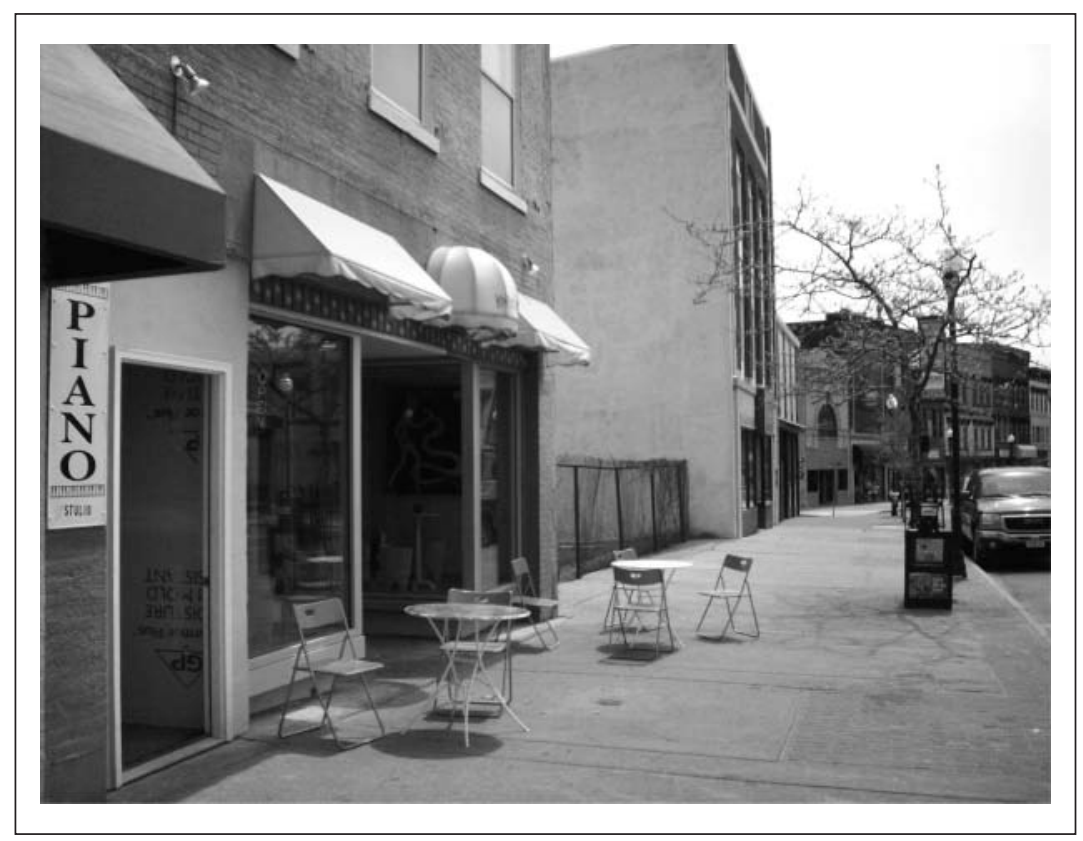

Figure 1. Plattsburgh, New York (2008). Personal photograph by Nicole LeFevre. 17 May 2008

The eight states were identified to represent a variety of regions, as well as states with varying levels of tobacco use (i.e., Arkansas, Kentucky, New Mexico, and Nevada all have smoking rates over 20\%, whereas California, Georgia, New York, and Vermont all have smoking rates below 20\%). ${ }^{1}$

The researchers worked in pairs, with one researcher identified as the "observer" and the second researcher identified as the "interviewer.” The researchers' goal was to 
stay at a location until they had observed 30 disposers. The mean amount of time spent on site was $4 \mathrm{hr}$ and $42 \mathrm{~min}$. Observations were mainly conducted on weekends because all observations took place outside and we expected more pedestrian traffic over weekends. But we also scheduled a few observations for weekdays. Observation times typically began in the morning to enable a long observation period, if needed.

Both researchers initially took a few photographs of each site (see Figures 1 and 2 as examples). They were instructed to take photographs of any litter and/or trash receptacles in the site but to avoid photographing specific, identifiable individuals.

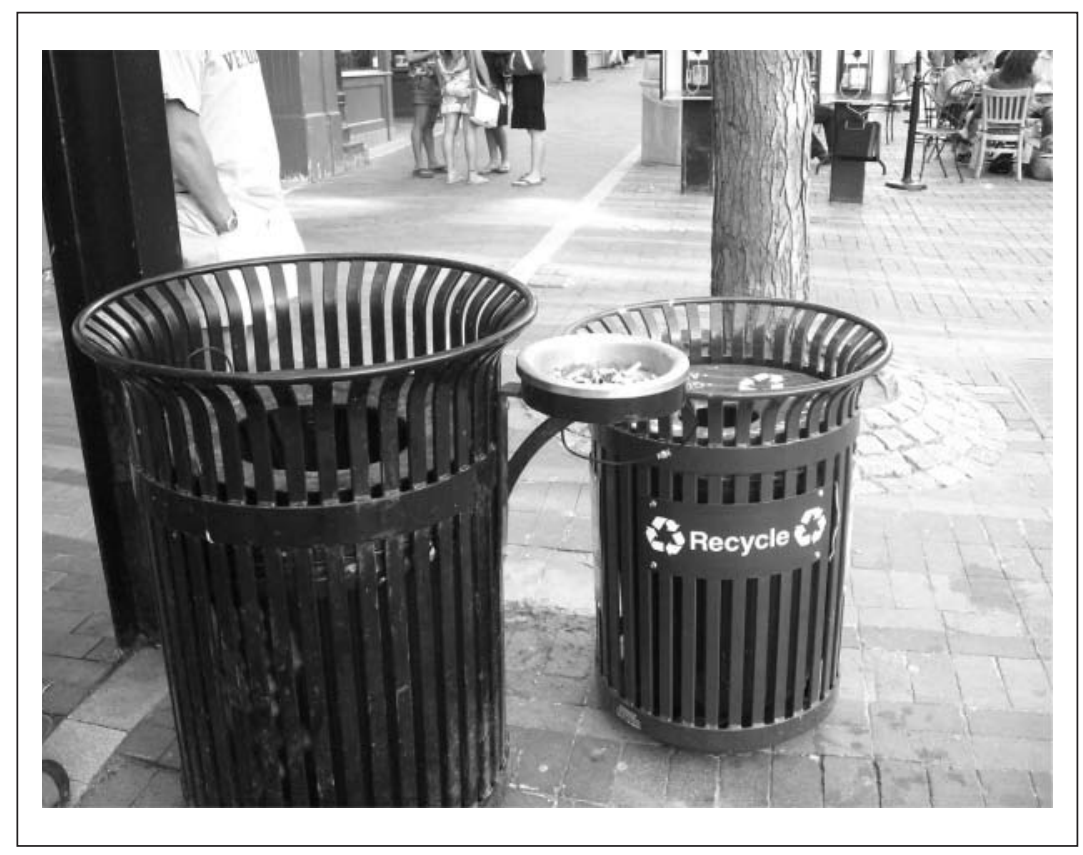

Figure 2. Burlington,Vermont (2008). Personal photograph by Montgomery Bopp. 19 April 2008

Researchers then recorded details about the built environment previously shown to be relevant to littering, including litter receptacle availability, and messages related to littering or smoking. The researchers then rated the amount of litter in 
each setting using a scale from 0 (not at all littered) to 10 (extremely littered). Discrepancies were resolved through discussion. Potentially important covariates, including weather, temperature, density of people present, and efforts to enhance the aesthetics of the location (e.g., pedestrian access, landscaping, and infrastructure), were also recorded.

The observer randomly selected participants by identifying the Nth individual to pass by the observation location. The $N$ was determined based on density of people in the location, with a range of options from 1 to 6 . The observer recorded whether or not the participant was in a group and observed one of three disposal options: The participant had no object to dispose, the participant left the site with the object, or the participant disposed of an object. No further recordings were made of participants who had no object to dispose of or who left the site with the object. The observer made additional recordings for only those participants who disposed of an object, and specifically noted (a) whether it was disposed of properly or improperly,

(b) the type of object disposed, (c) the disposal method or littering strategy, and (d) the participant's distance from receptacles.

When the observer identified a possible respondent, the observer contacted the interviewer using a hands-free cell phone device. In this way the interviewer was unaware of whether a potential respondent had just littered or made a proper disposal. The interviewer told each possible respondent that he or she was conducting research on community issues and offered US\$5 for responses to the survey. Only those respondents who self-reported being older than 18 years were included in the sample. The interviewer then asked each respondent to respond to a variety of questions related to littering verbally.

\section{Survey Measures}

We opened the survey by asking two distractor questions: (1) "What brings you here today?” (2) "In a typical month, how 
often do you come here?” The purpose of these questions was to reduce possible demand characteristics. Instead of immediately asking about littering behavior after observing the participant dispose of an item, we hoped that these distractor questions would reduce defensiveness among participants and increase accurate responses to our key measures. The next question asked the respondent to report how important the issue of litter is in that location using a scale from 0 (not at all important) to 10 (extremely important). Then participants were asked to estimate the percent of people who litter in this location. The following four items asked whether the respondent had seen or heard a specific message in the past year: about litter prevention, about a scheduled community clean up, messages discouraging cigarette butt litter, and any messages simply telling people "do not litter." Response options for those four items were "yes" or "no." If the respondent answered with a "yes" to any of those four items, the interviewer asked the respondent to think of the most recent message and describe where it was seen or heard. The interviewer coded each respondent's open-ended verbal answer into one of the following categories: PSA on the radio, PSA/commercial/news report on TV, billboard, newspaper, community flyer/bulletin, from a friend/family member, or other.

The interviewer then asked each respondent to respond verbally to an abridged version of the PNAL Scale (Cialdini et al., 1991). This shortened version of the scale asked respondents to rate their personal obligation to not 
Table 2. Statistical Test Results of the Hypotheses

\begin{tabular}{|l|l|l|}
\hline \multicolumn{1}{|c|}{ Hypotheses } & Result & Significance \\
\hline $\begin{array}{l}\text { Less littering will occur when } \\
\text { receptacles are present }\end{array}$ & Confirmed & $p<.05$ \\
\hline $\begin{array}{l}\text { Less littering will occur when } \\
\text { receptacles are nearby }\end{array}$ & Confirmed & $p<.001$ \\
\hline $\begin{array}{l}\text { Less littering will occur when } \\
\text { there is less litter present }\end{array}$ & $\begin{array}{l}\text { Not } \\
\text { confirmed }\end{array}$ & \\
\hline $\begin{array}{l}\text { Less littering will occur } \\
\text { among people who are alone }\end{array}$ & $\begin{array}{l}\text { Not } \\
\text { confirmed }\end{array}$ & \\
\hline $\begin{array}{l}\text { Does overall crowding of the } \\
\text { site impact littering? (fewer } \\
\text { other people at the site among } \\
\text { those who littered) }\end{array}$ & Confirmed & $p=.001$ \\
\hline $\begin{array}{l}\text { Older people will litter less } \\
\text { than younger people }\end{array}$ & Confirmed & $p=.008$ \\
\hline $\begin{array}{l}\text { Non litterers will have } \\
\text { stronger antilittering personal } \\
\text { norms }\end{array}$ & Confirmed & $p<.01$ \\
\hline
\end{tabular}

litter under five different situations: (1) You are holding an empty soft drink can, and there are no trash cans available; (2) you are holding a gum wrapper, and there are no trash cans available; (3) to stop and pick up a piece of scrap paper that blows off a big stack of papers you are carrying with both arms; (4) to not litter when you are ill (fever, headache, muscle ache), and you would have to walk out of your way to reach a trash receptacle; and (5) to pick up a piece of paper you dropped when it's raining and you are getting soaked. The interviewer provided a visual laminated scale anchored from 0 (no personal obligation) to 10 (very strong obligation). Respondents were also asked to estimate what percent of people at their location litter.

The interviewer then asked each respondent whether he or she had littered in the past month, and if so where, what the item was, and the reason. Respondents who had reported that they 
were aged more than 21 years were asked additional questions about smoking ("Do you smoke?" "When you smoke out- side, how do you dispose of cigarette butts?” “Do you consider cigarette butts to be litter?”). The last questions asked for each respondent's birth year and highest grade of school completed. The respondent was then thanked for his or her participation and given US\$5. After the interview was completed and the respondent had left the site, the interviewer recorded the respondent's gender.

\section{Results}

In terms of the hypotheses specified in the overview section, the statistical test results are presented in Table 2.

Overall, one fourth of all disposals observed were improper; in other words, 25\% of all disposals were littering $(n=25)$. Among those who littered, the most commonly littered object was cigarette butts. Nearly half $(n=14,45 \%)$ of all cigarettes disposed were littered. Of those who littered, most littering was intentional ( $n=20,80 \%$ ). The sample of people who agreed to participate in this intercept study was generally representative of the larger observational pool (of 130 sites with nearly 10,000 observations). For instance, in the larger study $81 \%$ of litter was coded as intentional (80\% of litter was coded as intentional in this intercept study), 57\% of cigarette butts were littered (45\% in this intercept study), and $17 \%$ of all disposals were improper (25\% in the intercept study).

\section{Built Environment Characteristics}

All sites ( $n=14$ sites) had at least one trash receptacle. The most common type of receptacle found was an uncovered trash can (71\% of sites had at least one uncovered trash can, $n=10)$, followed by a trash can/ashtray combo (43\% of sites had at least one trash can/ashtray combo, $n=6)$, and recycling bins (36\% of sites had at least one recycling bin, $n=5)$. There were significantly fewer trash receptacles at sites where people littered $\left(M_{\mathrm{L}}=4.4, S D=3.6\right)$ compared to sites where people did not litter $\left(M_{\mathrm{NL}}=6.1, S D=3.6\right), t(100)=2.1, p<.05$. At the time of disposal, participants were at an average distance of 8 feet from the nearest trash can, 37.7 feet from the nearest 
recycling bin, and 23.7 feet from the nearest ashtray. Consistent with previous findings regarding receptacle proximity, litterers were significantly farther from a trash can at the time of disposal than non-litterers $\left(M_{\mathrm{L}}=21.1\right.$ feet, $S D=20.8$ vs. $M \mathrm{NL}$ $=3.9$ feet, $S D=12.3), t(100)=-5.06, p<.001$. Only two of the sites (14\%) had posted signage regarding littering, whereas four (29\%) had posted signage regarding smoking. There was no trend for littering to occur less frequently at settings with posted signage about littering, $\chi^{2}(1)<1$ ns. Nor did littering occur less frequently at settings with posted signage about smoking, $\chi^{2}(1)=2.1$, ns.

Implicit Norm for Littering

All sites $(n=14)$ were found to have at least some litter in the setting; the mean amount of litter found in the settings was $M=$ $3.2(S D=1.9)$, using the scale from 0 (not at all littered) to 10 (extremely littered). Surprisingly, there was no significant difference in the amount of litter present at sites where people littered compared to the sites where people did not litter, $t(100)$ $<1$ ns.

The sites were evaluated quite positively in terms of their overall cleanliness $(M=6.9, S D=2.1)$, walk-ability $(M=8.1$, $S D=1.3)$, landscaping $(M=6.8, S D=2.5)$, and infrastructure $(M=7.4, S D=1.5)$. All ratings were made on scales ranging from 0 (not at all clean, not at all walkable, not at all landscaped, low infrastructure) to 10 (extremely clean, extremely walkable, extremely landscaped, high infrastructure).

\section{Litter Types and Strategies}

The most common type of litter found was cigarette butts (79\% of sites had cigarette butts, $n=11$ ), followed by paper and food wrappers (both were reported at $64 \%$ of sites, $n=9$ ). The mean amount of cigarette-butt litter found in the settings was $M=3.9$ $(S D=2.5)$, using the scale from 0 (not at all littered with cigarette butts) to 10 (extremely littered with cigarette butts). The number of cigarette butts present at each site ranged from 3 to 600 butts $(M=83, S D=165)$. 


\section{Individual Differences}

There was no difference among littering rates of men versus women. About $24 \%$ of men $(n=14)$ were observed to have littered, which was $26 \%$ in the case of women $(n=11), \chi^{2}(1)<$ $1 \mathrm{~ns}$. In terms of age, there was, however, a highly significant difference between litterers and those who did not litter. Those who littered were significantly younger than the nonlitterers $\left(M_{\mathrm{L}}=31\right.$ years, $S D=10 \mathrm{vs} . M_{\mathrm{NL}}=39$ years, $\left.S D=13\right), t(87)$ $=2.74, p=.008$.

There was a nonsignificant trend for litterers to be alone rather than in a group ( $N=15,60 \%$ were alone). Nonlitterers were more likely to be in a group (i.e., walking with at least one other person) rather than alone ( $n=44,57 \%$ were in a group). During the entire observation period, perceptions of the overall crowding at the site changed as other pedestrians walked into and out of the site. The minimum perception of how crowded a site was during observations was reported to be a mean of 3.23 $(S D=2.7)$, whereas the maximum perception of how crowded a site was during observations was found to be a mean of 6.69 $(S D=2.5)$. These ratings were made on a scale ranging from 1 $=$ minimum crowdedness to $10=$ maximum crowdedness. There was a significant difference between those who littered and those who did not litter in terms of how crowded the setting was, at both the minimum measure of crowdedness and at the maximum measure of crowdedness. The minimum and maximum measures of crowdedness were highly correlated $(\alpha=$ .76); therefore, these two items were averaged into an overall measure of crowdedness. Those who littered were in significantly less crowded settings $\left(M_{\mathrm{L}}=4.5, S D=1.9\right)$ than nonlitterers $\left(M_{\mathrm{NL}}=6.1, S D=2.1\right), t(85)=3.1, p<.01$.

A similar measure for perceived crowding was an actual count of the number of people passing through the site during the observation period. The minimum average number of people at a site during observations was $12.6(S D=15.4)$, whereas the maximum average number of people was $45.1(S D=37.5)$. There was a significant difference between those who littered and those who did not litter in terms of the number of others present, at both the minimum count and at the maximum count. Like the measures of crowding, these two measures were 
highly correlated $(\alpha=.76)$. Therefore, the two items were averaged into an overall measure of number of others at the site. There were significantly fewer other people at the site among those who littered $\left(M_{\mathrm{L}}=24, S D=22.9\right)$ compared to the nonlitterers $\left(M_{\mathrm{NL}}=47, S D=24.2\right), t(85)=3.6, p=.001$.

Participants reported that the issue of litter was quite important at their given location $(M=8.3, S D=2.0)$.

Participants tended to overestimate the percent of others who litter there, predicting that on average $40 \%$ of pass- ersby in their location were likely to litter, whereas in reality the average was $25 \%$. There was no difference between those who littered and those who did not litter in terms of their estimates of the percent of others who litter, $t(100)<-1.3 \mathrm{~ns}$.

Cronbach's alpha was computed on the five items from the PNAL Scale (Cialdini et al., 1991), and it was found to be high $(\alpha=.87)$. Therefore, the five items were averaged together to form an overall measure of PNAL. The mean score on this scale (from 0 to 10$)$ was $8.61(S D=1.9)$. Litterers had significantly lower perceived personal obligation to not litter compared to nonlitterers $\left(M_{\mathrm{L}}=7.7, S D=2.8\right.$ vs. $M_{\mathrm{NL}}=8.9$, $S D=1.4), t(100)=3.0, p<.01$.

Overall, $43 \%$ of the participants $(n=43)$ disclosed that they had littered in the past month. Litterers were significantly more likely to admit that they had littered in the past month, $\chi^{2}(1)=$ $6.2, p=.01$. Interestingly, $64 \%(n=16)$ of those who were unobtrusively observed to have littered reported that they had littered in the past month, indicating that even though they litter, a sizable percentage know that littering is socially undesirable enough to not want to disclose engaging in the behavior. This is important information from the perspective of measuring littering behavior by self-report; that is, self-reports are likely to be an underestimate of actual behavior.

Those who reported that they had littered in the last month were most likely to specify that the item littered was cigarettes ( $40 \%$ of items littered were cigarettes, $n=17$ ). Over half of our sample $(n=52)$ reported that they smoke cigarettes. Participants reported their usual disposal method of cigarettes and their responses were categorized into appropriate (e.g., ashtray, 
pocket, trash), littered (e.g., ground, storm drain), or other (e.g., depends on whether an ashtray is available, field strip, which is a practice of separating the filter from the butt and keeping/disposing the parts separately, etc.). Nearly 64\% ( $n=$ 30) of the smokers reported that they usually make appropriate disposals of their cigarettes. Overall, 61\% $(n=60)$ of all respondents reported that they consider cigarettes to be litter. Interestingly, smokers were significantly more likely to consider cigarettes to be litter, $\chi^{2}(1)=32.5, p<.001$, with $96 \%$ $(n=50)$ of smokers versus $39 \%(n=11)$ of nonsmokers reporting that they considered cigarettes to belitter.

\section{A Multivariate Approach}

Our final analysis involved using the strongest set of univariate predictors of littering behavior in a multivariate model to compare the predictive utility of each variable controlling for the others. Specifically, we conducted a logistic regression where the dependent variable was whether or not a participant littered. The predictors in the model were age, antilittering norms, and distance to a trash receptacle. We initially wanted to include both distance to the nearest receptacle and number of receptacles in the model; however, the two variables were too highly correlated $(r=.60, p<.001)$ to do so, and distance to the receptacle was more highly correlated with littering. In the model with all three predictors, both distance to the receptacle and age of the participant were still significant. Specifically, the farther away the receptacle, the more likely a participant was to litter (OR=1.096, 95\% confidence intervals $[\mathrm{CI}]=$ 1.029 to 1.11 , Wald $\chi^{2}=11.74, p<.001$ ) and the older the participant, the less likely he or she was to litter (OR $=.942$, $95 \%$ CI $=0.895$ to 0.99 , Wald $\chi^{2}=5.48, p<.05$ ). Norms were no longer a significant predictor after accounting for distance to the receptacle and age $(\mathrm{OR}=.835,95 \% \mathrm{CI}=0.631$ to 1.10 , Wald $\chi^{2}=1.60, p=.21$ ). The logistic analog to $R^{2}$ in ordinary least squares regression (Hosmer \& Lemeshow, 1989, p. 148; Menard, 1995, p. 22) indicated that $47 \%$ of the model 
deviance in the logistic regression equation was accounted for by this set of predictors. It is interesting to note that age was significantly correlated with antilittering norms, such that older participants endorsed stronger antilittering norms $(r=.19, p=$ .05). Thus, when both are in the model, only age remains a significant predictor of having littered.

\section{Discussion}

The purpose of this research was to examine the littering behavior of pedestrians while simultaneously recording specific environmental factors, explicit and implicit social norms for littering, demographic characteristics of the participants, as well as their self-reported motivation to not litter. We found that one fourth of all observed disposals were inappropriate (i.e., littered) and that the most commonly littered item was cigarette butts. In terms of environ- mental factors, people were more likely to litter in locations with fewertrash receptacles. This finding is consistent with past research on the importance of providing an adequate number of trash receptacles (e.g., Finnie, 1973; Meeker, 1997) and the implication of this finding is that it is important to make receptacles available. In addition to the availability of receptacles, we also found that people were more likely to litter in locations where they had to walk farther to reach a receptacle. This finding suggests that the placement of receptacles can be a key factor in preventing litter. We recommend thoughtful consideration of pedestrian traffic, such that receptacles are positioned in locations where they will be most easily accessible.

Although other researchers have consistently found littering to occur more often in littered settings (e.g., Cialdini et al., 1990; Finnie, 1973), our results did not support this trend. There are a few possible explanations for this finding. The amount of litter in the settings was evaluated using a scale from 0 (not at all littered) to 10 (extremely littered), and interestingly 60 of the 102 observations occurred in settings that were rated a “2.” This lack of variability reduces our power and diminishes our ability to find a significant effect. In the full observational 
sample of 130 sites, observed littering was correlated with the amount of existing litter in the site. This is probably because there was more variability across the 130 sites. A review of the literature reveals that most studies that find effects for the amount of litter in the setting have incorporated an experimental design with the amount of litter in the setting manipulated to be completely clean or completely littered. Another possible reason for the finding in the past research is that many of these studies did not provide trash receptacles. In the Cialdini et al. (1990) series of studies on descriptive norms, the authors manipulated the state of the environment to be littered or clean, but no receptacles were available. To refrain from littering participants had to hold onto the potentially littered item. Finnie compared littering rates with receptacles available versus not available across clean versus littered settings. He found a 51\% littering rate in a littered setting with no receptacle available, whereas only 33\% littered in a similar setting with a receptacle available. Given this caveat (and the fact that all of our sites had receptacles available), we encourage antilittering campaigns to follow the advice of those researchers who have found that littering occurs more often in littered settings, but to be certain receptacles are made available.

We found interesting results in terms of how the presence of other people affects one's decision to litter. Individuals were not differentially likely to litter depending on whether or not they were in a group. But we did find that littering changed depending on how crowded the location was. People tended to refrain from littering in locations that were more crowded. Though past research has found that people tend to be more “prosocial” when they are alone (e.g., Latané \& Darley, 1969), most of that work focused on the presence of others within one's social group or who are immediately nearby, rather than examining overall site crowding. We speculate that people may refrain from littering when sites are more crowded because there is an increased risk of being noticed or "caught." We encourage future researchers to test this hypothesis using a 
controlled experimental design.

To examine individual difference characteristics, we considered both demographic and personality factors. We did not find a gender difference in terms of littering behavior, but we did find that younger people were more likely to litter, even after controlling for distance to the nearest receptacle. This is consistent with past research (e.g., Durdan et al., 1985; Finnie, 1973; Heberlein, 1971; Keep America Beautiful, 1968; Krauss et al., 1978), with the trend explained as a result of maturity leading to normative control. Indeed, older participants in our sample endorsed stronger antilittering norms. Lindén (1996) considered that older generations are typically raised with less affluence and have attitudes about being careful with material resources. Conversely, younger generations’ attitudes result from upbringing with relatively greater affluence. These different backgrounds could lead younger individuals to exhibit more "wasteful” behavior. This raises an interesting questiondo the age-difference data reflect cohort effects or developmental variation? We encourage future researchers to investigate this issue to identify whether young litterers today are likely to refrain when they are older. In any case, given that younger individuals in our study were more likely to litter, antilittering campaigns are advised to direct their appeals to those younger than 30 (the median age of those who littered in the current research was 27.5 years). Our examination of personality factors relied on the use of an abridged version of the PNAL Scale (Cialdini et al., 1991). We found that those who littered reported significantly lower perceived personal obligation to not litter. This is especially useful considering that a substantial number of those who were observed to litter then went on to self-report that they had not littered in the past month. Apparently the PNAL Scale has increased predictive validity over a direct “yes" or "no” question.

Our study is certainly not without limitations, chief among them the observational design and cross-sectional nature of the data. Furthermore, we note that there were discrepancies in the number of observations obtained across sites, 
owing primarily to the density of the population in the locations observed. Nevertheless, it is possible that while the external validity of our study is very high, our findings may be somewhat more applicable to or representative of the sites from which we acquired a larger number of observations. Finally, we have to consider the possibility that our two distractor questions at the beginning of the survey were not enough to reduce demand characteristics. Perhaps adding more distractor questions could have attenuated this problem. But we wanted to make the intercept survey as brief as possible to achieve complete responses to all of our key measures. Although accurate responses are certainly a priority, we would encourage future researchers to consider techniques to reduce demand characteristics while keeping the survey brief.

\section{Conclusion}

Across 14 different sites in a total of eight states, we interviewed 102 disposers to examine how littering behavior is affected by environmental factors, social norms, demographic characteristics, and self-reported motivations. This research contributes much-needed external validity to the existing empirical literature on littering behavior. The main findings of the current study point to three key pieces of advice for those attempting to promote litter-free environments. First, it is essential that trash receptacles are available and easily accessible. Given that cigarette butts were by far the most littered items, we recommend further research to determine ways to most effectively provide cigarette butt receptacles to decrease litter of this type. Second, although we did not find heavier littering in more littered settings, this trend is so well established in the literature that we continue to suggest that this normative information does affect behavior, particularly in circumstances where receptacles are more difficult to access. Third, the PNAL Scale has been found to identify those most prone to littering, and we have both validated the scale with an 
unobtrusive measure of actual behavior (i.e., the PNAL Scale was significantly associated with having littered) and demonstrated that younger individuals are less likely to have strong antilittering norms. Social marketing researchers are encouraged to use this scale to isolate those at-risk for littering behavior, along with an approach that targets those most likely to have antilittering norms, that is, young people. We encourage future researchers to use experimental manipulations to establish the internal validity of these findings.

Authors' Note

Thanks are due to Lori Brown Large, Coral Bruni, and Jennifer Tabanico for their help in the development and execution of this project. We would also like to thank Sara Aguilar, Jenna Albert, Montgomery Bopp, Kara Carpenter, Cassie Fortney, Tracey Galea, Stefan Klimaj, Nicole LeFeve, Elizabeth Morales, Belinda Rojas, and Jenna Tonelli for collection of data.

\section{Declaration of Conflicting Interests}

The author(s) declared no potential conflicts of interest with respect to the research, authorship, and/or publication of this article.

\section{Funding}

The author(s) disclosed receipt of the following financial support for the research, author- ship, and/or publication of this article:

The first and third authors received funding from Keep America Beautiful, Inc., with a grant from Philip Morris USA, an Altria Company. This research was conducted in col- laboration with Action Research, Inc.

Note

1. This intercept study was part of a larger study of littering 
behavior conducted at over 130 locations nationwide.

Details about the larger study can be found in Schultz, Bator, Large, Bruni, and Tabanico (2009). Littering behavior in America. Manuscript submitted for publication. 


\section{References}

Bator, R. J. (1997). Effective public service announcements: Linking social norms to visual memory cues. Unpublished doctoral dissertation, Arizona State University.

Casey, P. J., \& Scott, K. (2006). Environment concern and behaviour in an Australian sample within an ecocentricanthropocentric framework. Australian Journal of Psychology, 58, 57-67.

Cialdini, R. B., Kallgren, C. A., \& Reno, R. R. (1991). A focus theory of normative conduct: A theoretical refinement and reevaluation of the role of norms in human behavior. In M. Zanna (Ed.), Advances in experimental social psychology (Vol. 24, pp. 201-234). New York: Academic Press.

Cialdini, R. B., Reno, R. R., \& Kallgren, C. A. (1990). A focus theory of normative conduct: Recycling the concept of norms to reduce littering in public places. Journal of Personality and Social Psychology, 58, 1015-1026.

Durdan, C. A., Reeder, G. D., \& Hecht, P. R. (1985). Litter in a university cafeteria: Demographic data and the use of prompts as an intervention strategy. Environment and Behavior, 16, 387-404.

Finnie, W. C. (1973). Field experiments in litter control. Environment and Behavior, 5, 123-144.

Geller, E. S., Brasted, W., \& Mann, M. (1980). Waste receptacle designs and interventions for litter control. Journal of Environmental Systems, 9, 145-160. 
Geller, E. S., Witmer, J. F., \& Tuso, M. A. (1977).

Environmental interventions for litter control. Journal of Applied Psychology, 62, 344-351.

Heberlein, T. A. (1971). Moral norms, threatened sanctions and littering behavior.

Unpublished doctoral dissertation, University of Wisconsin, Madison.

Hosmer, D. W., \& Lemeshow, S. (1989). Applied logistic regression. New York: John Wiley.

Kallgren, C. A., Reno, R. R., \& Cialdini, R. B. (2000). A focus theory of normative conduct: When norms do and do not affect behavior. Personality and Social Psychology Bulletin, 26, 1002-1012.

Keep America Beautiful. (1968). Who litters - and why.

Krauss, R. M., Freedman, J. L., \& Whitcup, M. (1978). Field and laboratory studies of littering. Journal of Experimental Social Psychology, 14, 109-122.

Latané, B., \& Darley, J. M. (1969). Bystander “apathy.”

American Scientist, 57, 244-268. Lindén, A. L. (1996). From word to action. Individual opportunities and societal restrictions. In L. J. Lundgren (Ed.), Livsstil och miljö. fråga, forska, förändra

(pp. 67-99). Stockholm, Swedish: Naturvårdsverkets förlag. Meeker, F. L. (1997). A comparison of table-littering behavior in two settings: A case for contextual research strategy. Journal of Environmental Psychology, 17, 59-68. Menard, S. (1995). Applied logistic regression analysis. Newbury Park, CA: SAGE.

Reich, J. W., \& Robertson, J. L. (1979). Reactance and norm appeal in anti-littering messages. Journal of Applied Social Psychology, 9, 91-101.

Reiter, S. M., \& Samuel, W. (1980). Littering as a function of prior litter and the presence or absence of prohibitive signs. 
Journal of Applied Social Psychology, 10, 45-55.

Schultz, P. W., Bator, R., Large, L. B., Bruni, C., \& Tabanico,

J. (2009). Littering behavior in America. Manuscript

submitted for publication.

Zelezny, L. C., Chua, P., \& Aldrich, C. (2000). Elaborating on gender differences in environmentalism. Journal of Social Issues, 56, 443-457.

Bios

Renée J. Bator is an associate professor and co-chairperson in the psychology department at the State University of New York, Plattsburgh. She completed her bachelor's degree in psychology at the University of California at Santa Cruz. She earned her $\mathrm{MA}$ and $\mathrm{PhD}$ from the social psychology program at Arizona State University. Her research interests focus on the application of persuasion theory to prosocial outcomes, especially those with environmental or health benefits.

Angela D. Bryan, PhD, received her BA in psychology from UCLA and her MA and PhD in social psychology with a quantitative emphasis from Arizona State University. She is currently professor of psychology at the University of New Mexico. The broad goals of her work are to use biopsychosocial models of health behavior to design, implement, and evaluate theory-based behavior change interventions to improve preventative health behavior. She currently studies HIV/STD prevention and exercise promotion. Highly innovative aspects of her work involve using functional magnetic resonance imaging (fMRI) and DNA collection to test key genetic and neurocognitive moderators of intervention effects and examine theory-based linkages between biological and social factors. 
P. Wesley Schultz is professor of psychology at California State University, San Marcos. His research interests are in applied social psychology, particularly in the area of sustainable behavior. Recent books include Social Psychology: An Applied Perspective (2000, Prentice-Hall), Psychology of Sustainable Development (2002, Kluwer), and Attitudes and Opinions (2005, Lawrence Erlbaum). His current work focuses on social norms, and the importance of social norms in fostering sustainable behavior. He has worked on projects for a variety of organizations, including the Environmental Protection Agency, National Institute of General Medical Science, National Institute of Justice, and the California Integrated Waste Management Board. 